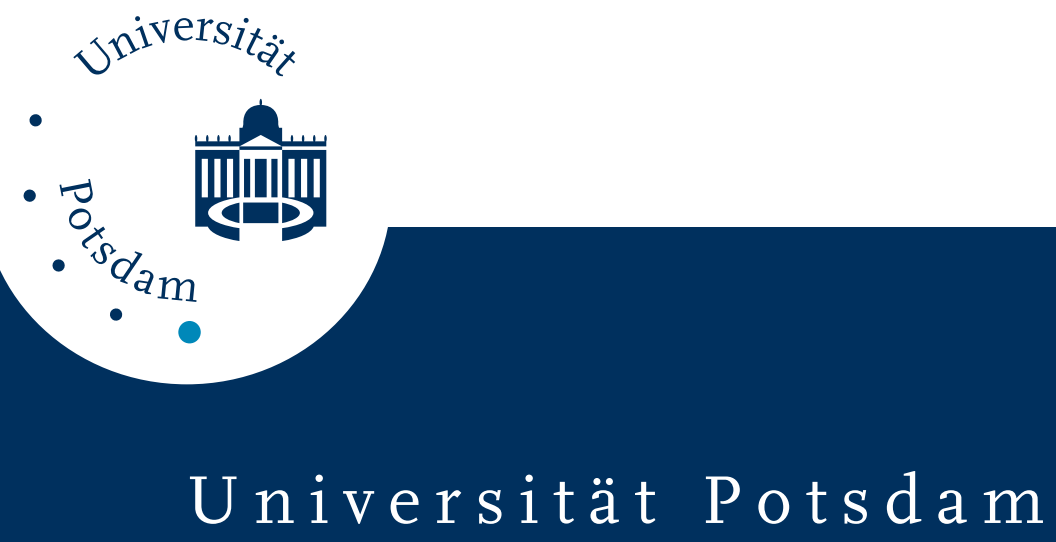

Erdelen, C.; Laschewsky, André; Ringsdorf, H.; Schneider, J.; Schuster, A.

\title{
Thermal behaviour of polymeric Langmuir-Blodgett multilayers
}

first published in:

Thin Solid Films, 180 (1989) S. 153-166, ISSN 0040-6090;

DOI 10.1016/0040-6090(89)90067-9

Postprint published at the Institutional Repository of Potsdam University:

In: Postprints der Universität Potsdam

Mathematisch-Naturwissenschaftliche Reihe ; 80

http://opus.kobv.de/ubp/volltexte/2008/1737/

http://nbn-resolving.de/urn:nbn:de:kobv:517-opus-17378

Postprints der Universität Potsdam

Mathematisch-Naturwissenschaftliche Reihe ; 80 


\title{
THERMAL BEHAVIOUR OF POLYMERIC LANGMUIR-BLODGETT MiULTILAYERS
}

\author{
C. ERDELEN, A. LASCHEWSKY, H. RINGSDORF, J. SCHNEIDER AND A. SCHUSTER \\ Institut für Organische Chemie, Universität Mainz, D-6500 Mainz, Postfach 3980 (F.R.G.) \\ (Received April 24, 1989; accepted May 25, 1989)
}

Langmuir-Blodgett multilayers of hydrocarbon and fluorocarbon polymers with hydrophilic spacer, lipid-polyelectrolyte complexes and mesogenic polymers have been prepared. The thermal behaviour of the multilayers was studied by small angle X-ray scattering, IR and UV-visible spectroscopy. Good thermal stabilities were found for the various classes of polymers. In addition, for both complexed multilayers and mesogenic polymer films, reorientation processes were observed.

\section{INTRODUCTION}

The stability of conventional Langmuir-Blodgett (LB) films against environmental influences such as solvents, vacuum and, especially, heat ${ }^{1,2}$ has been known to be rather low. Therefore, polymerization has been widely used to enhance film stability. The classical route to polymeric multilayers is the transfer of monomeric amphiphiles through the LB technique followed by polymerization on the substrate by irradiation with $\gamma$ rays or UV light ${ }^{3-5}$. This method is of limited use since structural changes during the polymerization can cause defects in LB films ${ }^{6-11}$. Consequently, polymerized LB films may demonstrate reduced thermal stability, contrary to expectations ${ }^{9,11}$.

An alternative method is spreading of prepolymerized amphiphiles and subsequent construction of multilayers ${ }^{12-15}$. This technique avoids structural changes due to the polymerization reactions, as well as providing additional options, e.g. it increases the variety of useful compounds since the whole range of polyreactions known can be used to tailor make polymers in advance of the selforganization process ${ }^{16,17}$. The primary drawback of this method is poor selforganization of conventional polymers since the polymer backbone hinders the efficient packing of the hydrophobic side-chains ${ }^{14,16}$. This problem has recently been overcome by the "spacer concept", i.e. incorporation of flexible hydrophilic spacer units into preformed polymers, thus decoupling the motion of the polymer backbone from the self-organization of the amphiphilic side-groups ${ }^{13,14,18,19,43}$.

To increase thermal stability of LB multilayers, we have studied the influence of the polymer structure on the thermal behaviour of LB multilayers built from 
functionalized "spacer" polymers. By varying the hydrophilic components as well as the hydrophobic side-chains, several polymers were prepared and investigated, including fluorocarbon polymers and polymeric liquid crystals.

\section{MATERIALS AND METHODS}

\subsection{Materials}

Tables I and II summarize the compounds used. Hydrophilic spacer polymers $1^{14}, 2^{18}, 3^{14}, 4-8^{20}, 9^{14}, 10^{14}$ and $11-18^{21}$ were synthesized according to the references given. All polymers were characterized by microanalysis, IR and ${ }^{1} \mathrm{H}$ nuclear magnetic resonance spectroscopy. The composition of the statistical copolymers was determined by microanalysis.

Dioctadecyldimethylammonium bromide (DODA-Br) was supplied by Kodak and poly(methacrylic acid) (PMAAc) by Röhm. Poly(sodium 4-styrenesulphonate) (PSS), poly(acrylic acid) (PAAc) and dihexadecylphosphate (DHP) were purchased from Aldrich. Poly(4-methyl vinylpyridinium iodide) (PMVP-I) was a gift of J. Zöller, and poly(2-trimethylammonium ethylmethacrylate bromide) was provided by B. Schlarb (both at the University of Mainz). The lipid-polyelectrolyte complexes were prepared at the air-water interface by spreading the lipid onto a $10 \mathrm{mg}^{-1}$ polyelectrolyte containing aqueous subphase.

\subsection{Phase behaviour}

The phase behaviour of the bulk polymers was studied with a Perkin-Elmer DSC-2C instrument and a transmission polarized light microscope (Ortholux II Pol-BK; Leitz). The microscope was equipped with a Mettler FP52 hot stage controlled by an FP5 unit.

\subsection{Film preparation}

Monolayer experiments were performed on computer-controlled film balances $^{22}$. The water was purified first by distillation, then filtration through a Milli-Q water purification system (Millipore Corp.). Amphiphiles were spread either from chloroform or, in the case of polymers 1-10, from chloroform-methanol mixtures ( $9: 1$ by volume) to enhance solubility. Fluorocarbon homopolymer 4 was spread from Freon-113. The concentration of the solutions was about $0.5 \mathrm{mg} \mathrm{ml}^{-1}$.

LB multilayers were prepared on commercially available film balances (Lauda, Joyce Loebl, KSV). All polymeric amphiphiles were transferred from pure aqueous subphases at $20^{\circ} \mathrm{C}$. A variety of substrates such as thin polyester foils (Hostaphan RE 3,0; Kalle) backed up by a Teflon plate ${ }^{23}$, fused quartz microscope slides (Suprasil; Hereaus-Schott, Fisher), zinc selenide disks, $200 \mathrm{~nm}$ of silver or aluminium evaporated onto microscope slides and silicon wafers (Si 100; Wacker) were used for film deposition ${ }^{19}$. After each dipping cycle, the supports were completely pulled out of the subphase and the samples were allowed to dry to avoid retransfer of the previously deposited monolayers during the next downward dip.

\subsection{Characterization of multilayers}

Multilayers on polyester foils were examined by glancing angle X-ray 


\section{TABLE I}

HYDROPHILIC SPACER POLYMERS

Hydrocarbon and fluorocarbon polymers

Hydrocarbon side-chains

Functionalized side-chains
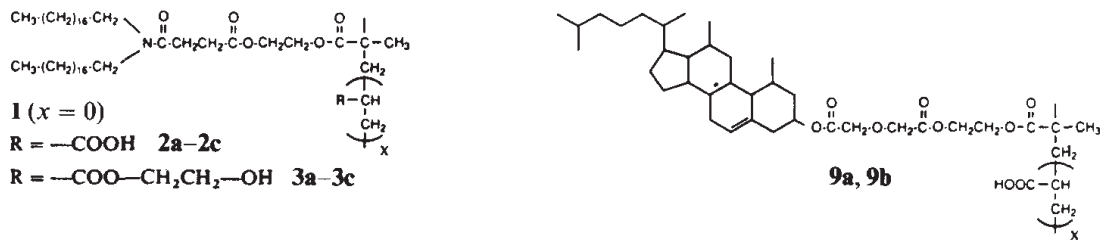

Fluorocarbon side-chains

$$
x=0,5
$$

$$
\begin{aligned}
& \mathrm{F}_{3} \mathrm{C} \cdot\left(\mathrm{CF}_{2}\right)-\mathrm{CH}_{2}-\mathrm{CH}_{2}-\mathrm{OOC}-\mathrm{C}-\mathrm{CH}_{3}
\end{aligned}
$$

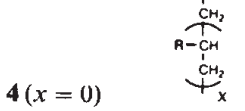

$$
\begin{aligned}
& \mathbf{R}=-\mathrm{COOH} \quad \mathbf{5 a}-\mathbf{5 c} \\
& \mathrm{R}=-\mathrm{COO}-\mathrm{CH}_{2}-\mathrm{CH}_{2}-\mathrm{OH} \quad 6 \mathrm{a}-6 \mathrm{c} \\
& \mathrm{F}, \mathrm{C} \cdot \mathrm{CF}_{2} \mathrm{hl}_{\mathrm{n}}-\mathrm{CH}_{2} \cdot \mathrm{CH}_{2}-\mathrm{O} \cdot \stackrel{\mathrm{O}}{\mathrm{C}}-\mathrm{NH}-\mathrm{CH}_{2} \cdot \mathrm{CH}_{2}-\mathrm{OOC}-\frac{1}{\mathrm{C}}-\mathrm{CH}_{3} \\
& 7 \mathbf{a}-7 \mathbf{d}(n=7) \\
& 8 \mathbf{a}-8 \mathbf{d}(n=9)
\end{aligned}
$$

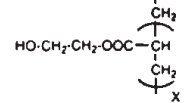

$$
\begin{aligned}
& x=0,1,5,10
\end{aligned}
$$

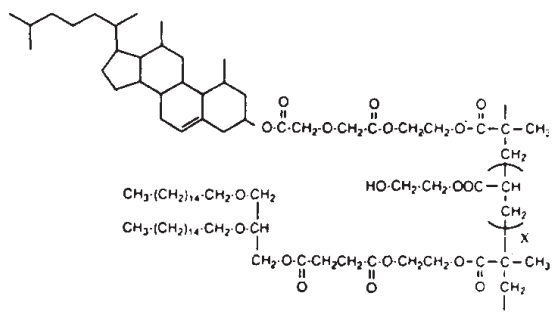

10a, 10b

$$
x=0,10
$$

Mesogenic side-chain polymers

By polycondensation

By polymerization

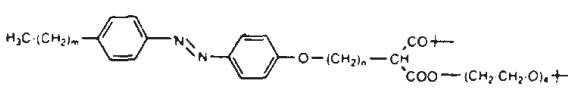

$m=7,3$

11a, 11b

$n=6,10$
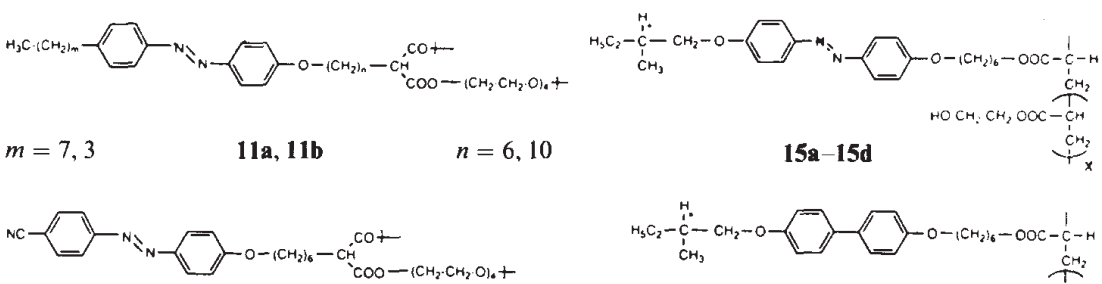

12
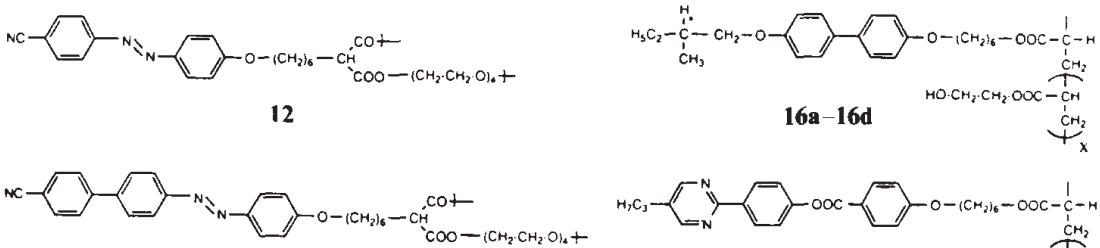

13
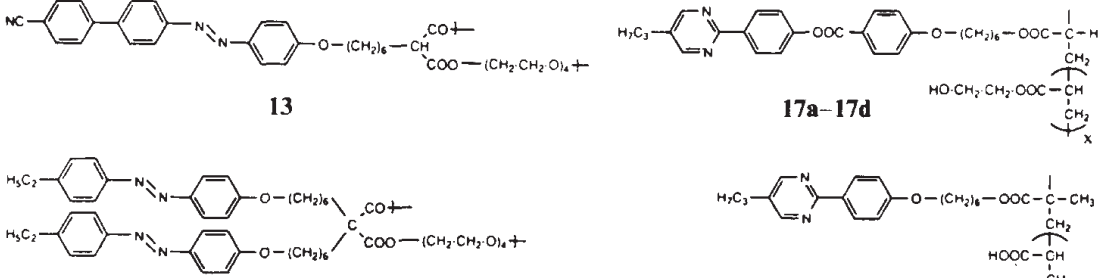

14

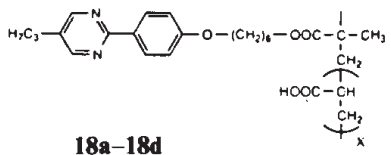

$x=0,1,5,10$ 
TABLE II

LIPID-POLYELECTROLYTE COMPLEXES

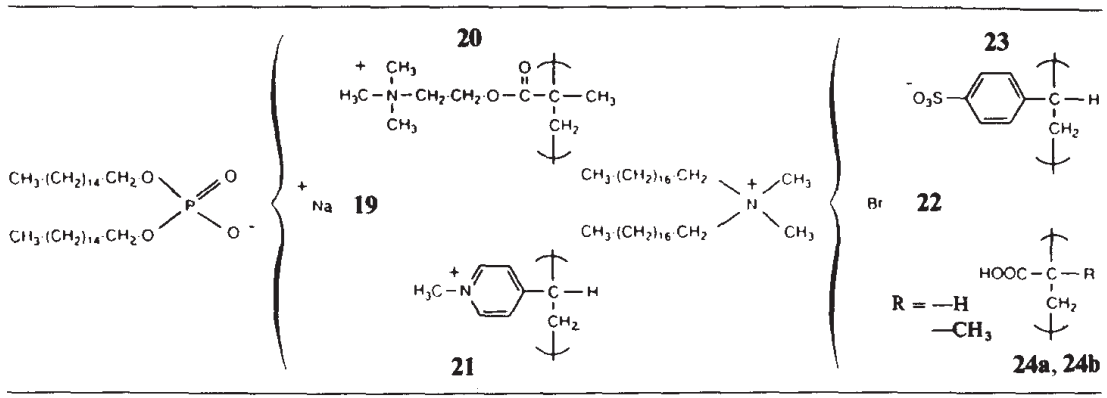

diffraction (Siemens type D-500 diffractometer) using the nickel-filtered $\mathrm{Cu} \mathrm{K} \alpha$ line $(0.1541 \mathrm{~nm})$. The equipment had variable temperature capability.

The details of the Fourier transform IR (FTIR) experiments have been described previously ${ }^{19}$.

For UV-visible spectroscopic investigations, multilayers were built on quartz slides. The spectra of the lipid-polyelectrolyte complexes were recorded with a Perkin-Elmer Lambda 5 spectrophotometer at room temperature. Variable temperature studies of mesogenic polymer multilayers ${ }^{24}$ were performed with a Varian Cary 2290 spectrophotometer equipped with a heating chamber.

\section{RESULTS AND DISCUSSION}

\subsection{Langmuir-Blodgett multilayers from hydrocarbon spacer polymers}

The spreading behaviour of hydrocarbon spacer polymers and the deposition of LB multilayers has been studied in detail previously ${ }^{14,18,25}$. It was shown that high quality multilayers can be obtained. The thermal stability of such polymeric LB multilayers was studied by small angle X-ray scattering (SAXS) and polarized IR spectroscopy ${ }^{18,19}$. All these multilayers exhibited a characteristic increase in

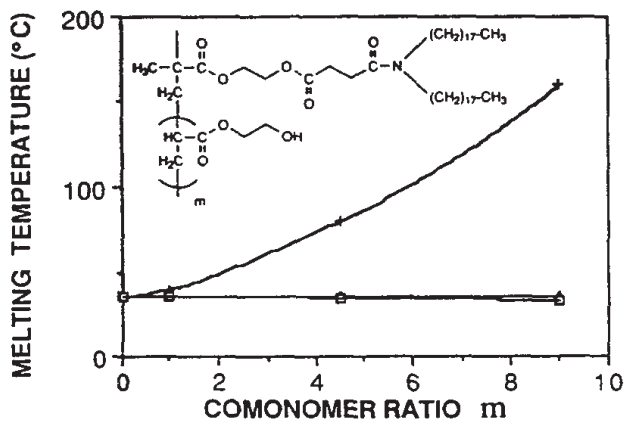

Fig. 1. Thermal stability of LB multilayers from polymers 1 and $\mathbf{3 a - 3}$ studied by SAXS and grazing incidence angle reflection (GIR)-FTIR spectroscopy compared with thermal bulk behaviour measured by differential scanning calorimetry (DSC): +, SAXS; $\mathbf{A}$, GIR-FTIR; $\square$, DSC. 
thermal stability with increasing amounts of hydrophilic comonomer incorporated. Figure 1 shows a comparison of the results of the different methods. Obviously, the melting of the hydrocarbon side-chains studied in bulk by DSC and in multilayers by IR is virtually the same for a set of copolymers, although the melting temperature of the multilayer structure seen by SAXS increases steady with the comonomer content. This indicates that, by appropriate design of the polymers, the stability of the multilayer structure is not limited by the melting of the hydrophobic side-chains. The reasons for the improved stability are not fully clear yet. Presumably, this can be attributed to electrostatic interactions and hydrogen bonding, giving rise to lamellar microphase separation into an unpolar "soft" block and a polar "hard" block. The exceptionally high stability of multilayers built from copolymers containing high amounts of hydroxyethylacrylate (HEA) may be caused by additional cross-linking at elevated temperatures via transesterification.

\subsection{Langmuir-Blodgett multilayers from lipid-polyelectrolyte complexes}

As long known for surfactant-polyelectrolyte complexes, charged monolayers can also be stabilized by complexation with polyelectrolytes ${ }^{26,27}$. In analogy to the spacer polymers described above, these complexes can be considered as polymers with "ionic spacers". Because of the strong interaction of the polymeric counterions with the charged monolayer, it is possible to transfer these lipid-polyelectrolyte complexes onto solid supports ${ }^{28-30}$. A schematic diagram of such complexed monolayers and LB multilayers is shown in Fig. 2. Various combinations of charged lipids using polyelectrolytes as counterions which build complexed LB multilayers were studied for their thermal stability, as summarized in Table II.
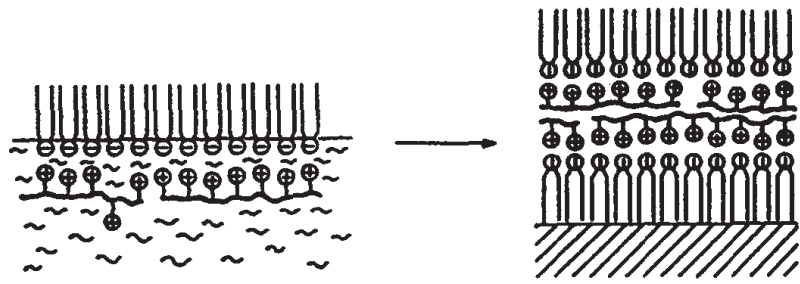

Fig. 2. Schematic diagrams of monolayers and LB multilayers built from lipid-polyelectrolyte complexes.

In the case of compounds $\mathbf{2 1}$ and $\mathbf{2 3}$, only the polyelectrolytes are UV active, but not the lipids DHP-Na (sodium salt of DHP) 19 and DODA-Br 22. Thus the linear increase in the UV absorbance of the prepared LB multilayers indicates successful complexation and reproducible monolayer transfer. This is illustrated for complex 21 (DHP-PMVP) in Fig. 3. Analogous results were obtained with the DODA-PSS complex 23. The detailed composition of these complexed LB multilayers is unknown.

Comparative SAXS studies of LB multilayers from the DHP-Na salt 19 with those from the DHP-PMVP complex 21 at $20^{\circ} \mathrm{C}$ reveal an increase in the $d$ spacing on complexation, from $3.4 \mathrm{~nm}$ for films of DHP-Na salt 19 to $5.4 \mathrm{~nm}$ for films of complex 21 (Figs. 4 and 5). In addition to the 001 reflection, both SAXS diagrams 


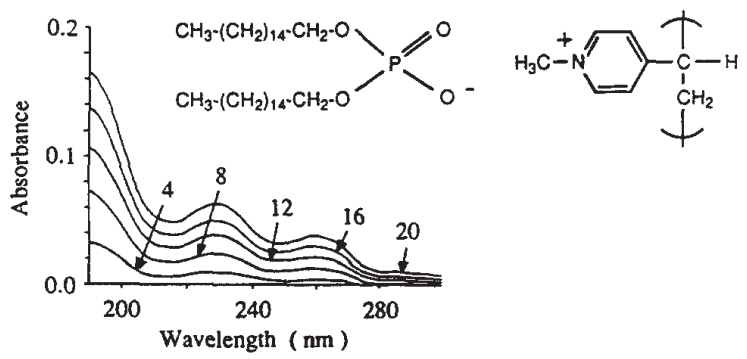

Fig. 3. Linear increase in UV absorbance of LB multilayers of lipid-polyelectrolyte complex 21 with the number of layers (4-20 layers on quartz).
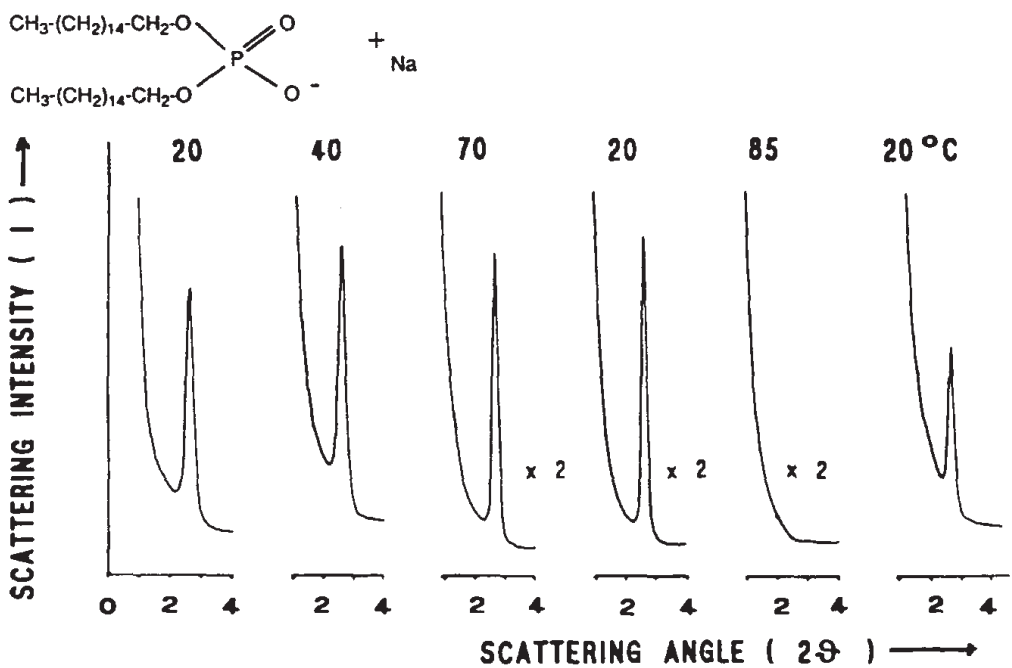

Fig. 4. Variable temperature SAXS study of LB multilayers from DHP-Na salt 19 (30 layers on polyethylene terephthalate (PET)).

exhibit higher reflection orders indicating a well-ordered LB multilayer structure with high layer correlation.

Apparently, anionic DHP-Na monolayers are selectively complexed by polycations. If polyanions such as poly(sulphonic acids) are added to the subphase, no incorporation of polyelectrolytes into the LB multilayers was observed, and layers with a $d$ spacing $(3.4 \mathrm{~nm})$ and temperature stability $\left(c f\right.$. Fig. $\left.4 ; 80^{\circ} \mathrm{C}\right)$ identical to those of the DHP-Na lipid 19 were found.

In contrast to the literature ${ }^{31}$, we could not prepare coherent, good quality LB multilayers from the DODA-Br 22 on pure water subphase. However, on anionic electrolyte solutions (e.g. DODA-PSS complex 23) LB multilayer formation was easily achieved ( $d$ spacing, $4.2 \mathrm{~nm}$ ). From monolayers of DODA-Br 22 on cationic polyelectrolyte solutions, no LB film could be prepared, as observed on pure water subphase. This corresponds to the lack of complexation of anionic monolayers by polyanionic subphases. 


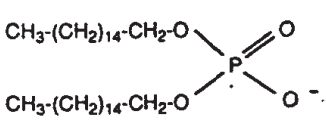

20

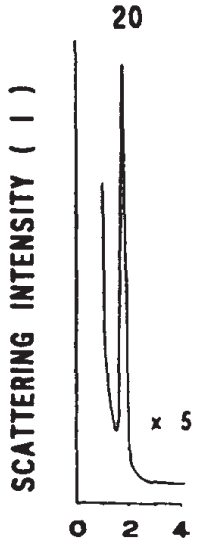<smiles>CCC(CC(C)C)c1cc[n+](C)cc1</smiles>

145
160

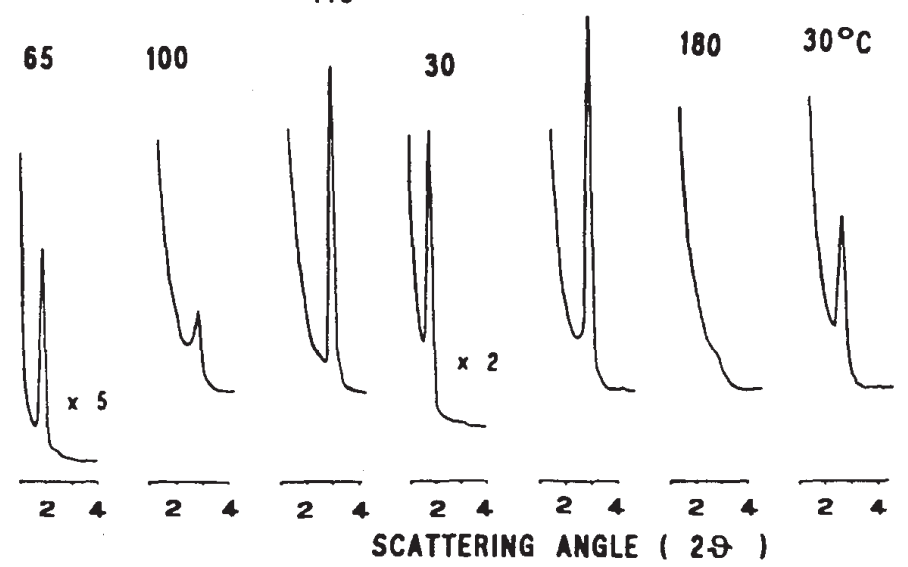

Fig. 5. Variable temperature SAXS study of LB multilayers from DHP-PMVP complex 21 (30 layers on PET).

The thermal stability of LB multilayers from the complexes $20,21,23,24 a$ and 24b was studied by SAXS. Figure 4 shows the results of a variable temperature study of LB films from the DHP-Na salt 19 with heating and cooling cycles. The layer reflection disappears above $80^{\circ} \mathrm{C}$, in good agreement with the bulk melting point. After cooling to room temperature only a partial recovery of the structure, full of defects, is observed. Figure 5 shows the results of a variable temperature study of LB films from the DHP-PMVP complex 21. According to the X-ray pattern, the complexation improves the temperature stability of the multilayer structure up to $160^{\circ} \mathrm{C}$. The melting of the LB structure occurs at $180^{\circ} \mathrm{C}$. After cooling to room temperature, a partial recovery is evident (Fig. 5). An interesting feature of the complexed LB film from 21 (Fig. 5) is the structural rearrangement starting at $100^{\circ} \mathrm{C}$. The original layer reflection with a $d$ spacing of $5.4 \mathrm{~nm}$ disappears and a new reflection occurs with less intensity and a smaller $d$ spacing of $3.1 \mathrm{~nm}$. The new structure anneals as shown by the improvement in signal intensity after heating to $145^{\circ} \mathrm{C}$. On cooling to room temperature, the original layer reflection ( $d$ spacing, $5.4 \mathrm{~nm}$ ) reappears. Heating cycles of $160^{\circ} \mathrm{C}$ induce structural rearrangement again, but irreversibly. Analogous results were obtained for LB films of complex 20.

As for anionic lipids and polycations, complexed LB multilayers were successfully prepared for cationic lipids and polyanions. The thermal stability of multilayers of DODA-PSS complex $23\left(\mathrm{ca} .100^{\circ} \mathrm{C}\right)$ is below those of the complexes 20 and 21, but is exceeded by multilayers of complexes with PAAc $24 \mathbf{a}^{32}$ and PMAAc $\mathbf{2 4 \mathbf { b } ^ { 3 2 }}$. Their thermal stabilities are comparable with that of DHP-PMVP 21. However, no structural rearrangement is observed, and the layer spacings of 
$3.2 \mathrm{~nm}$ and of $4.0 \mathrm{~nm}$, respectively, are constant through heating and cooling cycles up to $160^{\circ} \mathrm{C}$. The SAXS experiments with the complexed LB multilayers demonstrate their high potential for building stabilized LB films, thus representing an alternative approach to the use of polymeric spacer amphiphiles discussed above.

\subsection{Langmuir-Blodgett multilayers from fluorocarbon spacer polymers}

As discussed in previous sections, the thermal stability of polymeric multilayers is improved by appropriate modification of the hydrophilic region. Alternatively, modification of the hydrophobic side chains may be considered. Most notable differences are found when the hydrocarbon chains are replaced by fluorocarbon chains ${ }^{8,33-35}$. Differences are not restricted to thermal properties, but include also modified wettability, miscibility and permeability. Therefore, several sets of copolymers of fluorocarbon monomers with hydrophilic comonomers were prepared (Table I). The spreading behaviour of the resulting fluorocarbon spacer polymers corresponds qualitatively to their hydrocarbon analogues as discussed in detail elsewhere ${ }^{20}$. Figure 6 illustrates the monolayer behaviour of fluorocarbon amphiphiles 7a-7c, representative of this class of polymers. Characteristic for these compounds is the increase in the expanded phase with enlarged comonomer content. However, in all cases, densely packed monolayers are obtained at high surface pressures which can be transferred to build polymeric LB multilayers.

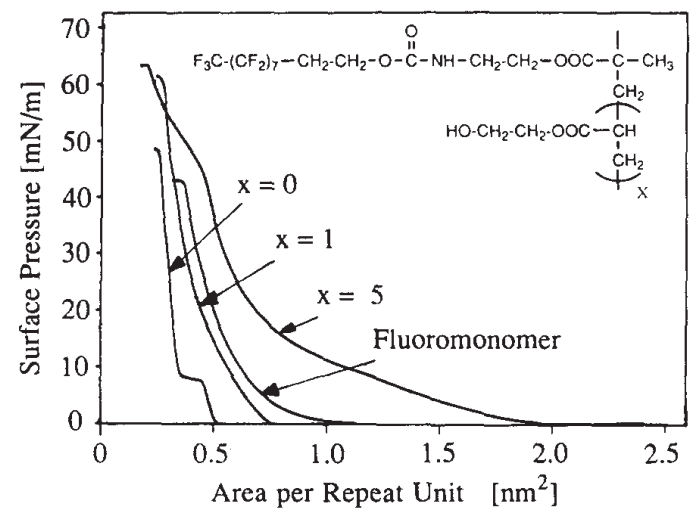

Fig. 6. Surface pressure-area diagrams of fluorocarbon polymers $7 \mathbf{a}-7 \mathbf{c}$ at $20^{\circ} \mathrm{C}$ on pure water subphase. Isotherm of monomeric fluorocarbon lipid included for comparison.

Thermal stability of polymeric fluorocarbon multilayers was investigated by SAXS (Fig. 7). The layer structure for copolymer $6 \mathrm{~b}$ melts just below $100^{\circ} \mathrm{C}$, thus exceeding the melting point of the hydrocarbon analogue $3 \mathbf{b}$, although the hydrophobic chains are much shorter. The high thermal stability of the polymeric fluorocarbon films is further indicated by thermodesorption experiments, proving film stability well above $200^{\circ} \mathrm{C}$. The multilayer structure is partially recovered on cooling (Fig. 7), in agreement with IR experiments ${ }^{20}$. Hence, functionalization of spacer polymers by fluorocarbon chains gives rise to thinner multilayers with improved thermal stability. 


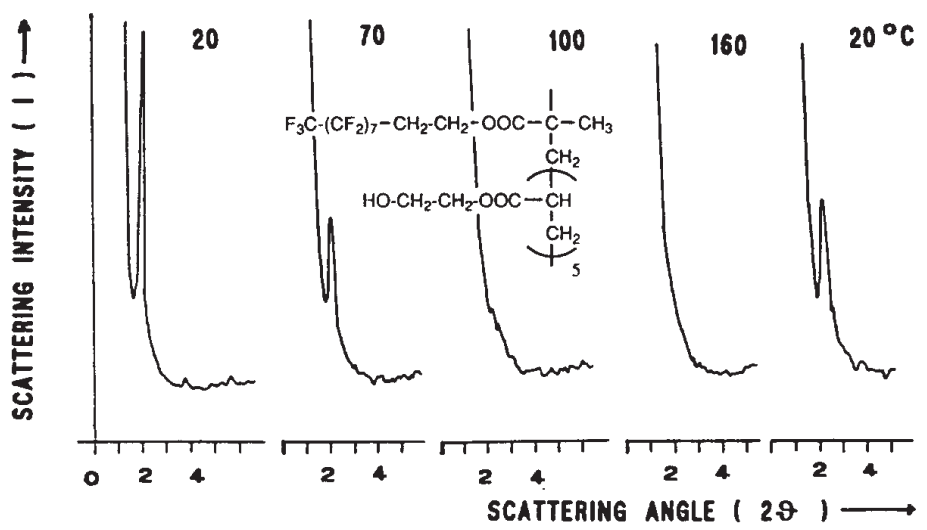

Fig. 7. Variable temperature SAXS study of LB multilayers from copolymer $6 \mathrm{~b}$ ( 30 layers on PET).

\subsection{Langmuir-Blodgett multilayers from mesogenic spacer polymers}

In addition to improved thermal stability, controlled manipulation of LB multilayers would be desirable, e.g. to produce single-crystal-domain multilayers. This would require mobility within LB films while the layer structure is simultaneously retained. At present, no such process is known.

Mobility and order are the characteristics of liquid crystals. Thus the combination of amphiphilic and mesogenic elements to bifunctional "amphotropic" molecules may result in manipulatable LB multilayers ${ }^{16,36}$, as already presented at the Third International Conference on Langmuir-Blodgett Films ${ }^{37}$. Because of their amphiphilic character, amphotropic molecules can be assembled into monolayers and LB multilayers, thus controlling the structure in the vertical direction. The additional mesogenic groups, introducing thermotropic liquid crystalline properties, may allow control of the lateral structure by external fields ${ }^{16}$.

Initially, polyester amphiphiles with mesogenic side groups 11-14 were investigated ${ }^{16,37}$, whose multilayers often have low melting temperatures. SAXS studies of LB films of, for example, polymer 11a indicate the melting of the layer structure already at $50^{\circ} \mathrm{C}$. Furthermore, microscopy of the films revealed the loss of the coherent coating once melted, although SAXS signals reappeared on cooling. These signals are derived from droplets of bulk material in its liquid crystalline phase (Table III) whose lattice spacing is identical to the $d$ spacing of the LB multilayers, giving the illusion that the multilayer structure has been retained. The rather low thermal stabilities of the polycondensate LB films are explained by their molecular structure. In contrast to polymers 1-10, the tetraethyleneglycol main chain of polymers 11-14 is not able to establish strong electrostatic interactions or hydrogen bonding to stabilize the multilayers, thus lowering the melting point.

LB films from mesogenic polymers are stabilized by very polar spacer groups analogous to polymers 1-10. Hence a variety of copolymers with hydrophilic main chain spacers and different mesogenic side-groups have been synthesized (15-18; Table I). All of these compounds form liquid crystalline phases in bulk. The transition temperatures of selected polyesters and vinyl polymers are listed in Table 
TABLE III

LIQUID CRYSTALLINE PHASE BEHAVIOUR OF SELECTED MESOGENIC POLYMERS

\begin{tabular}{|c|c|c|c|c|}
\hline Compound & $m$ & $n$ & $x^{a}$ & $\begin{array}{l}\text { Phase transitions }{ }^{\mathrm{b}} \text { and temperatures } \\
\left({ }^{\circ} \mathrm{C}\right)\end{array}$ \\
\hline $11 \mathrm{a}$ & 7 & 6 & - & $g-27 \mathrm{~s} 55 \mathrm{i}$ \\
\hline $11 \mathbf{b}$ & 3 & 10 & - & $\mathrm{k} 27 \mathrm{~s} 58 \mathrm{i}$ \\
\hline 12 & 一 & - & - & k $40(n 29) i$ \\
\hline 13 & - & - & - & $\mathrm{g}-15 \mathrm{~s} 119 \mathrm{~s}_{\mathrm{A}} 209 \mathrm{i}$ \\
\hline $15 a$ & - & - & 0 & k $76 s_{1} 101-104 s_{2} 108 i$ \\
\hline 15b & - & - & 1 & k 59 1c 76 s 88-94i \\
\hline $15 \mathrm{c}$ & - & - & 5 & g $13 \mathrm{k} 57 \mathrm{lc} 84 \mathrm{i}$ \\
\hline 15d & - & - & 10 & g $3-5 \mathrm{k} 56 \mathrm{lc} 75 \mathrm{i}$ \\
\hline
\end{tabular}

${ }^{a}$ Clearing points (transition from liquid crystalline to isotropic phase) of polymers 15 were assigned by polarized light microscopy.

${ }^{b} \mathrm{k}$, crystalline phase: $\mathrm{n}$, nematic phase; $\mathrm{s}$, smectic phase; g, glass transition; $1 \mathrm{c}$, unspecified liquid crystalline phase; i, isotropic phase.

III. It should be emphasized that the mesophase formation in the case of vinyl copolymers such as 15a-15d is unexpected. Generally, even small amounts of nonmesogenic groups within a liquid crystalline polymer suppress phase form$a^{a t i o n}{ }^{38-40}$. The existence of liquid crystalline phases may be attributed to microphase separation as reported for liquid crystalline poly(siloxanes) ${ }^{40}$.

Figure 8 presents the isotherms of the mesogenic polymer set $15 \mathrm{a}-15 \mathrm{~d}$ at $20^{\circ} \mathrm{C}$. The mesogenic groups have no obvious influence on the spreading behaviour of these polymers. The isotherms exhibit solid-analogue phases even at high comonomer contents. With increasing main chain spacer, starting at $x=5$, large fluid phases occur which expand with the comonomer concentration. These results correspond to those of monolayers of hydrocarbon and fluorocarbon spacer polymers ${ }^{18,20}$ (cf. Fig. 6). In the condensed state, the polymeric monolayers can be easily transferred onto supports. The linear increase in IR absorbance of LB films from 15c (Fig. 9) underlines the uniform and reproducible transfer. The higher absorbance of the $\mathrm{CH}_{2}$ stretching mode at $2920 \mathrm{~cm}^{-1}$ in the parallel polarized IR spectra (Fig. 10) prove the preferred alignment of the $\mathrm{CH}_{2}$ bonds parallel to the support ${ }^{19,41}$. This points to a nearly perpendicular arrangement of the hydrophobic side-chains in the multilayers. Most interestingly, the freshly prepared LB films exhibit an additional in-plane dichroism for most transmission IR bands (Fig. 11). If the IR beam is polarized parallel to the dipping direction, more intense modes of the $\mathrm{C}-\mathrm{O}-\mathrm{C}$ ether bonds and of the $\mathrm{C}=\mathrm{C}$ aromatic ring vibrations are observed. Since both modes have their transition dipole moment in the long axis of the mesogen ${ }^{42}$, a preferred alignment of the mesogen in the dipping direction is inferred.

The thermal behaviour of LB films of polymers 15 and 17 was studied by polarized IR and UV spectroscopy ${ }^{24}$. It was found that the in-plane IR dichroism in Fig. 11 vanishes irreversibly on annealing at $150^{\circ} \mathrm{C}$. The spectra are independent of polarization direction and lie between the extremes shown in Fig. 11. In contrast to the polycondensate 11a, microscopy shows intact films after the annealing process. This means that reorientation of amphiphiles in LB films was achieved without film 


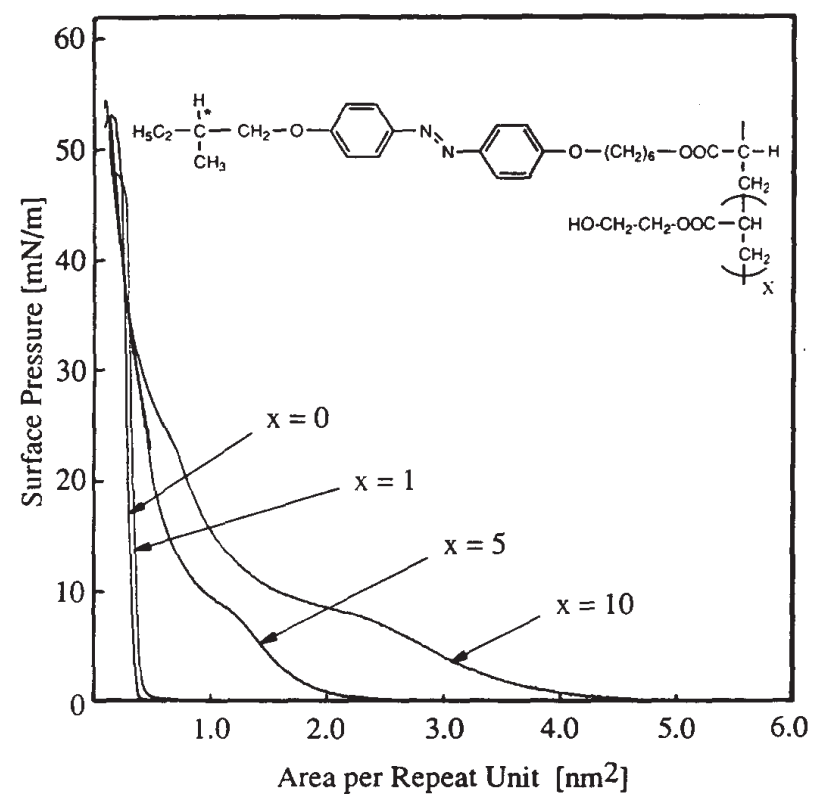

Fig. 8. Surface pressure-area diagrams of chiral mesogenic spacer polymers $15 \mathfrak{a}-15 d$ on pure water subphase at $20^{\circ} \mathrm{C}$.
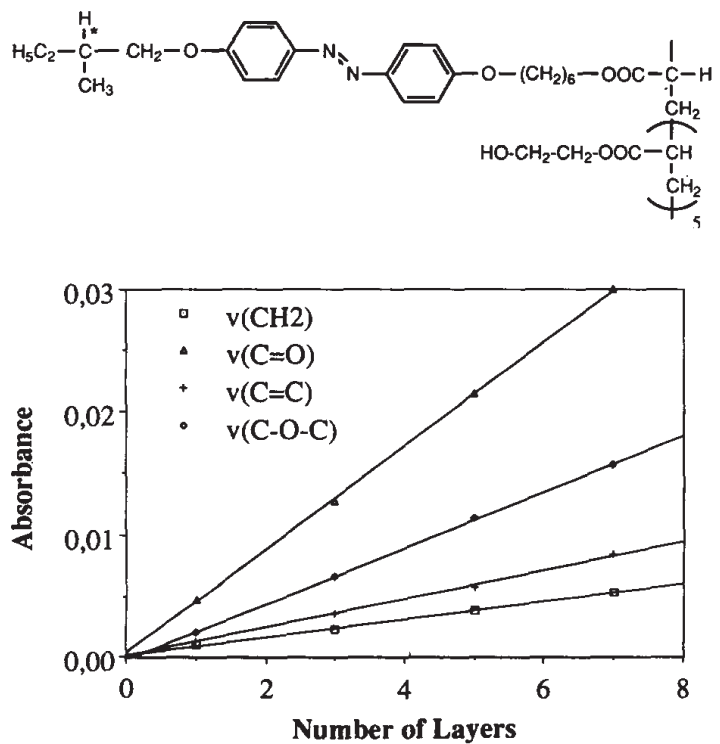

Fig. 9. IR spectroscopy of LB multilayers from copolymer $15 \mathrm{c}$ at $20^{\circ} \mathrm{C}$. A linear increase in IR absorbance with number of layers for different vibration modes is observed (1-7 layers on aluminium). 

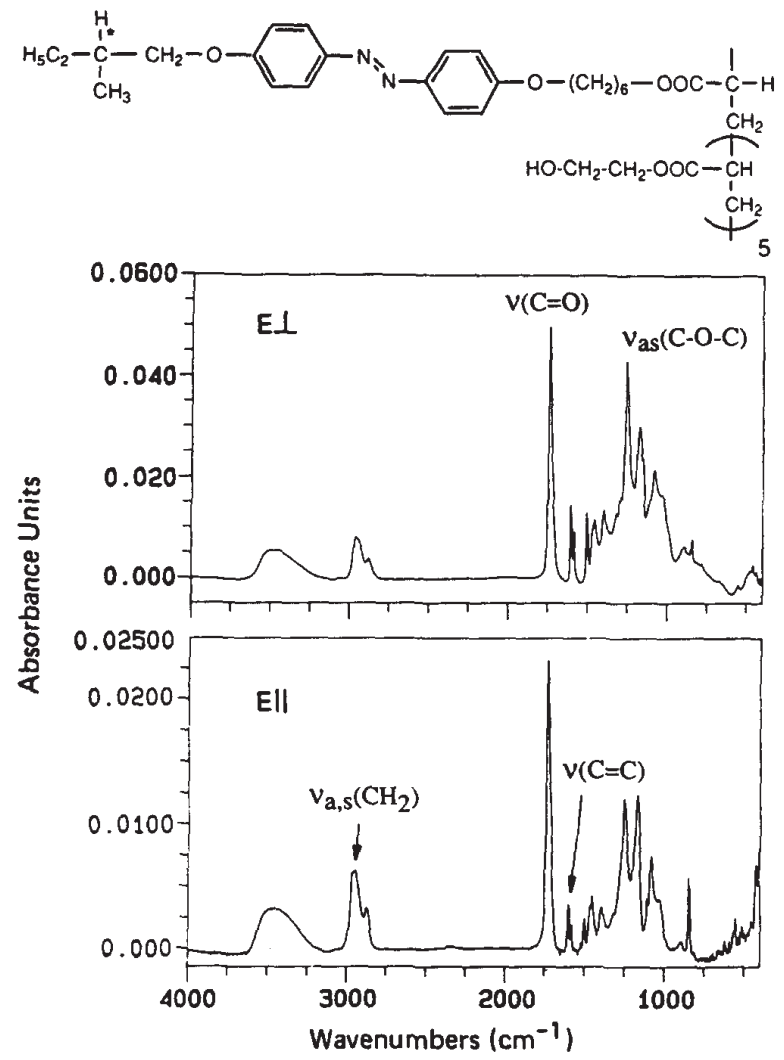

Fig. 10. Comparison of GIR-IR ( $\boldsymbol{E} \perp$, perpendicular to surface) and standard transmission IR ( $\boldsymbol{E} \|$, parallel to surface) measurements of LB films from mesogenic copolymer $15 c(E \perp, 9$ layers on aluminium; $\boldsymbol{t} \|, 35$ layers on silicon; resolution, $4 \mathrm{~cm}^{-1} ; 2000$ scans).

destruction. These findings are corroborated by polarized UV spectroscopy (Fig. 12). The in-plane dichroism of the mesogen observed in the freshly prepared films disappears irreversibly on annealing above $60^{\circ} \mathrm{C}$. In addition, a reversible thermochromism is observed just below $60^{\circ} \mathrm{C}$ (Fig. 12), which coincides with a phase transition in bulk (see Table III).

For mesogenic copolymers 15 and 17 , retention of coherent LB films during reorientation processes was found. These results are encouraging when keeping the concept of "amphotropic" LB multilayers ${ }^{16,37}$ in mind. Future investigations, e.g. by SAXS and electron diffraction, are necessary for a better understanding of the processes involved and their influence on the multilayer properties.

\section{CONCLUSIONS}

Amphiphilic spacer polymers form thermally stable multilayers even above the melting point of the hydrophobic chains. Complexation of charged lipids with 


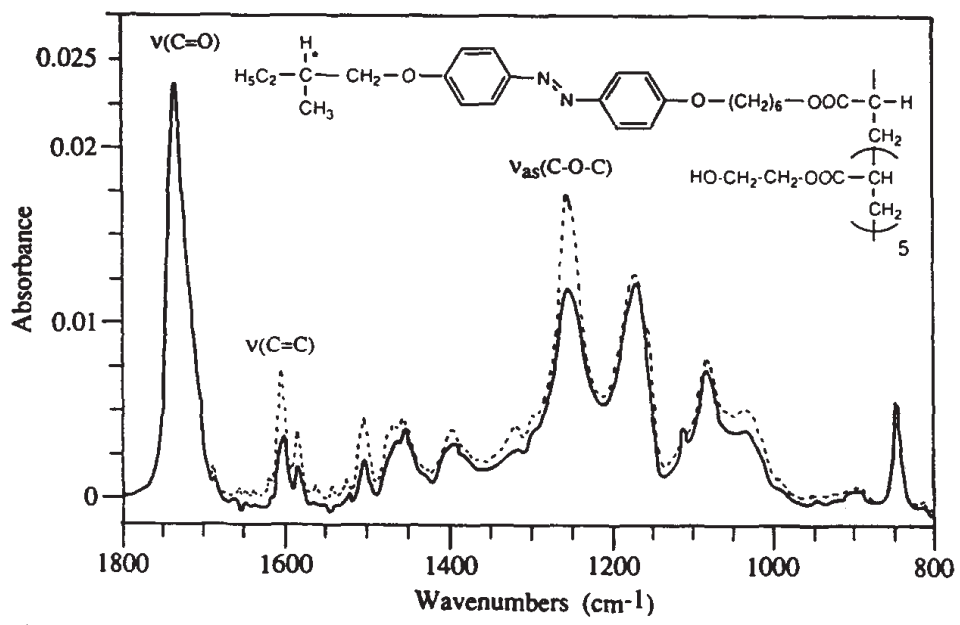

Fig. 11. Polarized transmission IR spectra of LB films of copolymer $15 \mathrm{c}$ ( 35 layers on silicon wafer at $20^{\circ} \mathrm{C}$ ) showing IR dichroism after the transfer process: - $-\boldsymbol{E}$ perpendicular to dipping direction; -..-, E parallel to dipping direction.

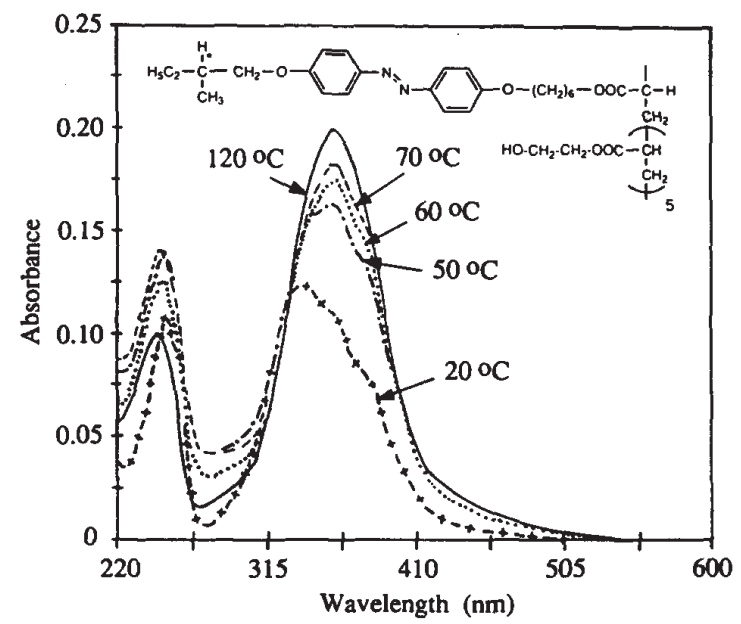

Fig. 12. Polarized UV spectra of LB films of polymer $15 \mathrm{c}$ at different temperatures measured up to $120^{\circ} \mathrm{C}$. Heating and cooling cycles are reversible (9 layers on quartz; $\boldsymbol{E}$ parallel to dipping direction).

oppositely charged polyelectrolytes leads to multilayers with improved thermal behaviour as well. Replacement of the hydrocarbon chains in spacer polymers by fluorocarbon chains enables formation of very thin thermostable LB multilayers with modified properties of the hydrophobic region. The functionalization of polymeric multilayers by mesogenic units results in thermostable LB multilayers, which offer the possibility of structural manipulation. 


\section{REFERENCES}

1 K. B. Blodgett, Phys. Rev., 55 (1939) 391.

2 T. Fukui, M. Sugi and S. Iizima, Phys. Rev. B, 22 (1980) 4898.

3 A. Cemel, T. Fort and J. B. Lando, J. Polym. Sci., Polym. Chem. Edn., I0(1972) 2061.

4 R. Ackermann, D. Naegele and H. Ringsdorf, Makromol. Chem., 175 (1974) 699.

5 K. Fukuda, Y. Shibasaki and H. Nakahara, Proc. 6th Int. Conf. on Surface-Active Substrates, Zürich, 1972, in Chemie, physikalische Chemie und Angwendungstechnik der grenzflächeraktiven Stoffe, Carl Hanser Verlag, Munich, 1973, Vol. II/1, p. 273.

6 A. Barraud, Thin Solid Films, 99 (1983) 317.

7 M. Sarkar and J. B. Lando, Thin Solid Films, 99 (1983) 119.

8 A. Laschewsky, H. Ringsdorf and G. Schmidt, Thin Solid Films, 134 (1985) 153.

9 A. Laschewsky, H. Ringsdorf and G. Schmidt, Polymer, 29 (1988) 448.

10 B. Tieke, G. Lieser and K. Weiss, Thin Solid Films, 99 (1983) 95.

11 J. P. Rabe, J. F. Rabolt, C. A. Brown and J. P. Swalen, J. Chem. Phys, 84 (1986) 4096.

12 P. Hodge, E. Koshdel, R. H. Tredgold, A. J. Vickers and C. S. Winter, Br. Polym. J., 17 (1985) 368.

13 R. Elbert, A. Laschewsky and H. Ringsdorf, J. Am. Chem. Soc., 107 (1985) 4134.

14 A. Laschewsky, H. Ringsdorf, G. Schmidt and J. Schneider, J. Am. Chem. Soc., 109 (1987) 788.

15 G. Duda, A. J. Schouten, T. Arndt, G. Lieser, G. Schmidt, C. Bubeck and G. Wegner, Thin Solid Films, 159 (1988) 221.

16 H. Ringsdorf, B. Schlarb and J. Venzmer, Angew. Chem. Int. Edn. Engl., 27 (1988) 113.

17 C. S. Winter and R. H. Tredgold, Thin Solid Films, 134 (1985) 49.

18 M. B. Biddle, J. B. Lando, H. Ringsdorf, G. Schmidt and J. Schneider, Colloid Polym. Sci., 266 (1988) 806.

19 J. Schneider, H. Ringsdorf and J. F. Rabolt, Macromolecules, 22 (1989) 205.

20 J. Schneider, C. Erdelen, H. Ringsdorf and J. F. Rabolt, Macromolecules, (1989), to be published.

21 H. Ringsdorf and A. Schuster, to be published.

22 O. Albrecht, Thin Solid Films, 99 (1983) 227.

23 O. Albrecht, A. Laschewsky and H. Ringsdorf, Macromolecules, 17 (1984) 937.

24 T. Penner, A. Schuster, H. Ringsdorf and J. Schildkraut, Proc. 4th Int. Conf. on Langmuir-Blodgett Films, Tsukuba, 1989.

25 W. Frey, J. Schneider, H. Ringsdorf and E. Sackmann, Macromolecules, 20 (1987) 1312.

26 M. Pugelli and G. Gabrielli, Colloid Polym. Sci., 261 (1983) 82.

27 E. D. Goddard, Colloids Surf, 19 (1986) 301.

28 W. McNaughton, K. A. Snook, E. Caspi and N. P. Franks, Biochim. Biophys. Acta, $818(1985) 132$.

29 M. Shimomura and T. Kunitake, Thin Solid Films, 132 (1985) 243.

30 Y. Nishikata, T. Konishi, A. Morıkawa, M. Kakimoto and Y. Imai, Polym. J., 20 (1988) 269.

31 T. Kajiyama, A. Kumano, M. Takayanagi and T. Kunitake, Chem. Lett., (1984) 915.

32 H. Ringsdorf, M. Schmidt and J. Schneider, to be published.

33 R. Elbert, T. Folda and H. Ringsdorf, J. Am. Chem. Soc., 106 (1984) 7687.

34 T. Kunitake, Y. Okahata and S. Yasunami, J. Am. Chem. Soc., 104 (1982) 5547.

35 A. Sekiya, H. Ishida, M. Tamura and M. Watanabe, Chem. Lett., (1987) 1593.

36 R. Jones, R. H. Tredgold, A. Hoorfar, R. A. Allen and P. Hodge, Thin Solid Films, 134 (1985) 57.

37 H. Ringsdorf, J. Schneider and A. Schuster, Proc. 3rd Int. Conf. on Langmuir-Blodgett films, Göttingen, 1987.

38 V. P. Shibaev, Y. S. Freidzon and N. A. Plate, Vysokomol. Soedin., Ser. A, 20 (1978) 82.

39 H. Ringsdorf and A. Schneller, Br. Polym. J., 13 (1981) 43.

40 S. Diele, S. Oelsner, F. Kuschel, B. Hisgen, H. Ringsdorf and R. Zentel, Makromol. Chem., 188 (1987) 1993.

41 J. F. Rabolt, C. F. Burns, N. E. Schlotter and J. D. Swalen, J. Chem. Phys., 78 (1983) 946.

42 H. Nakahara and K. Fukuda, J. Colloid Interface Sci., 93 (1983) 530.

43 T. Kunitake, M. Nagai, H. Yanagi, T. Takarabe and N. Nakashima, J. Macromol. Sci., Chem. A, 2 I (1984) 1237. 